\title{
Duas sepulturas para um corpo: a disputa cristã pelo verdadeiro Santo Sepulcro
}

\author{
Magno Paganelli*
}

\section{Resumo}

Desde o final do século XIX, os evangélicos deixaram de visitar a Igreja do Santo Sepulcro, em Jerusalém, da tradição católico romana e ortodoxa, que arrogava a prerrogativa de ser o sepulcro onde o corpo de Jesus Cristo fora colocado após a sua retirada da cruz, segundo o Novo Testamento. Os grupos evangélicos passaram a considerar o chamado Calvário de Gordon como o verdadeiro local onde o evento do sepultamento ocorreu, há cerca de dois mil anos. Diante desse quadro, este artigo investiga a literatura de viagem dos primeiros séculos da presente era e a correspondência do General Gordon, do século XIX, a fim de identificar os indícios sobre a legitimidade de um dos locais. Embora os fiéis se apoiem na fé, os relatos considerados dão conta das mudanças arquitetônicas na antiga cidade de Jerusalém, promovidas em períodos diferentes, e que a fé evangélica não teria captado ao optar pela mudança do destino que arrasta anualmente cerca de 250 mil fiéis, conforme os dados disponíveis.

Palavras-chave: Santo Sepulcro. Igreja do Santo Sepulcro. Calvário de Gordon. Calvário. Jerusalém.

\section{Two Graves for a Body: The Christian Dispute for the True Holy Sepulcher}

\begin{abstract}
Since the late nineteenth century, evangelicals have ceased to visit the Holy Sepulcher Church in Jerusalem of the Roman Catholic and Orthodox tradition, which claimed the prerogative of being the sepulcher where the body of Jesus Christ was placed after his removal from the cross. according to the New Testament. Evangelical groups came to regard Gordon's so-called Calvary as the true place where the burial event took place about two thousand years ago. Against this background, this article investigates the travel literature of the early centuries of the present era and the correspondence of 19th century General Gordon to identify clues about the legitimacy of one of the sites. Although the faithful rely on the faith, the accounts considered account for the architectural changes in the ancient city of Jerusalem, carried out at different times, and
\end{abstract}

* Doutor em História Social (FFLCH-USP) e Bacharel em Teologia com Pós-graduação em Novo Testamento. E-mail: paganelli.magno@gmail.com 
which the evangelical faith would not have grasped by opting for the change of fate that drags about 250,000 believers annually, according to available data.

Keywords: Holy Sepulcher. Church of the Holy Sepulcher. Gordon's Calvary. Calvary. Jerusalem.

\section{Dos tumbas para un cuerpo: la disputa cristiana por el verdadero Santo Sepulcro}

\section{Resumen}

Desde finales del siglo XIX, los evangélicos han dejado de visitar la Iglesia del Santo Sepulcro en Jerusalén de la tradición católica y ortodoxa romana, que reclamó la prerrogativa de ser el sepulcro donde se colocó el cuerpo de Jesucristo después de su remoción de la cruz. De acuerdo con el Nuevo Testamento. Los grupos evangélicos llegaron a considerar el llamado Calvario de Gordon como el verdadero lugar donde tuvo lugar el entierro hace unos dos mil años. En este contexto, este artículo investiga la literatura de viajes de los primeros siglos de la era actual y la correspondencia del general Gordon del siglo XIX para identificar pistas sobre la legitimidad de uno de los sitios. Aunque los fieles confían en la fe, las cuentas consideradas explican los cambios arquitectónicos en la antigua ciudad de Jerusalén, llevados a cabo en diferentes momentos, y que la fe evangélica no habría captado al optar por el cambio del destino que arrastra a unos 250,000 creyentes anualmente, Según los datos disponibles.

Palabras clave: Santo Sepulcro. Iglesia del Santo Sepulcro. Calvario de Gordon. Calvario. Jerusalén.

\section{Introdução}

A população cristã mundial se divide em grupos, sendo os mais expressivos os católicos romanos, os ortodoxos ou orientais, e os protestantes. Cada tradição tem subdivisões que não cabe aqui nomeá-las. Todas preservam a fé comum de que o Cristo, o personagem que fundamenta a fé cristã, ressuscitou após três dias de sua crucificação, deixando um túmulo vazio na cidade de Jerusalém, segundo os Evangelhos e a tradição. Anualmente, milhões de turistas de todo o mundo, independentemente da tradição religiosa, visitam Israel (ISRAEL, 2017) ${ }^{1}$ e querem conhecer o local onde acreditam ter sido colocado o corpo de Jesus.

\footnotetext{
O Ministério do Turismo do país informa a composição para a massa de turistas: $54 \%$ cristãos (25\% visitam como peregrinos). Do total, 39\% são católicos, 33\% protestantes e $22 \%$ ortodoxos russos), $21,7 \%$ judeus e outras religiões ou não afiliados. Dos turistas, $41 \%$ estão em regresso, ou seja, já visitaram Israel e 29,8\% fazem parte de um grupo organizado (ISRAEL, 2017). Frossard apresentou os seguintes dados: "dos 2,8 milhões de turistas que Israel recebeu em 2010, 60\% eram cristãos. Do Brasil, especificamente [...] $80 \%$ eram evangélicos e $20 \%$ eram católicos [...] cerca de 40 mil fiéis evangélicos brasileiros embarcaram no ano de 2010 com destino a Israel". Miriane Frossard. Caminhando por terras bíblicas: religião, turismo e consumo nas caravanas evangélicas brasileiras para a Terra Santa [Tese Ciências da Religião], Universidade Federal de Juiz de Fora, 2013, p. 147.
} 
Há controvérsias entre a localização de sítios onde as histórias da tradição cristã teriam ocorrido e o que é apontado pelo Novo Testamento. Como assinala Julie Ann Smith: "Não há evidências de sobrevivência para qualquer conhecimento local ou tradicional do local da morte ou sepultamento de Cristo antes de 325 . O primeiro relato da identificação do Sepulcro está na Vida de Constantino de Eusébio, que relata isso depois do Concílio de Niceia (325)" (SMITH, 2007, p. 9). Para tornar a questão mais complexa, há em Jerusalém dois locais que reclamam ser o histórico túmulo. O mais antigo está localizado no interior da Igreja do Santo Sepulcro, sob administração de monges católicos romanos e ortodoxos gregos. O outro é conhecido como "Calvário de Gordon", em referência ao General Charles George Gordon, um militar inglês que no final do século XIX disse ter localizado o verdadeiro sítio fora dos muros da cidade velha de Jerusalém, que hoje é administrado pelo protetorado britânico na Terra Santa ${ }^{2}$ e recebe anualmente cerca de 250 mil visitantes.

Além das questões de fé e devoção, o tema envolve prestígio, reforça narrativas, amplia o capital político e os benefícios que o turismo confere. A receita com o turismo em Israel, ${ }^{3}$ em 2017 , foi de US $\$ 5,744$ bi, com record de 3,6 mi de turistas (MINISTÉRIO, 2018).

Considerando o breve quadro, queremos resgatar indícios que sustentem uma narrativa, a católica ou a evangélica. Para tanto, valemo-nos de revisão bibliográfica a partir de pesquisa previamente realizada, quando conferimos os relatos ou narrativas de viagem produzidos nos primeiros séculos da era cristã e depois disso, como demonstraremos.

\section{As narrativas ou relatos de viagem}

Para a historiografia, a literatura de viagem se constitui em "fonte" vasta, e por vezes única, das informações históricas: "Atividades cotidianas, organização urbana ou vida íntima" (TORRÃO FILHO, 2010, p. 58). Encontradas no trato da realidade, os autores de literatura de viagem registraram as rotinas comerciais, o trânsito e a economia internacional, a exploração colonial, como indicou a historiadora Karen Macknow Lisboa

The Garden Tomb (Jerusalem) Association. Home page em: http://www.gardentomb.com/. O turismo está entre os principais elementos que compõem o PIB de Israel, mas as informações são desencontradas. O Ministério do Turismo diz que gira em torno de 154 bilhões de dólares (51․ lugar no mundo), acessado em: 26.09.2015 e disponível em: <encurtador.com.br/pPX29>. O e-mail recebido do Ministério, três anos depois, diz \$ 20 bi de shekels, o que convertido em dólares dá US $\$ 5,744$ bi. 
(2011, p. 62). O relato analisado pela autora, de "Moritz Schanz, comerciante e viajante diletante", reúne o itinerário pretendido aos assuntos cotidianos em "uma combinação entre o relato clássico de viagem, em que o deslocamento físico através do espaço orienta a descrição, intercalados por momentos de reflexão e síntese, e um estudo de cunho por assim dizer sociológico” (LISBOA, 2011, p. 63).

Pela ampla produção, pelo volume produzido e a aceitação popular, relatos de viagem estabeleceram um perfil específico. Torrão Filho indicou a literatura de viagem como um "gênero" literário já consolidado, com estilo e estrutura interna própria, o que lhe confere especificidades que o historiador deve captar a fim de extrair o material para compor sua pesquisa (TORRÃO FILHO, 2010, p. 37-38) e recompor a história. Se questionarmos sobre a marca principal da literatura de viagem, temos em Lisboa a seguinte definição: "grosso modo, o deslocamento do autor pelo espaço físico, por tempo determinado, implicando um retorno ao 'seu' lugar de origem e a transformação do observado e do vivido em narrativa" (LISBOA, 2011, p. 82; grifos no original). Lisboa faz a ressalva de que tal definição não esgota as possibilidades. Há autores que se estabeleceram no destino e ali viveram o restante de suas vidas, como Stefan Zweig e sua esposa Lotte (suicidaram-se no Rio de Janeiro em 1941) e (Santa) Paula, que depois de uma peregrinação que durou dois anos e após viver cerca de 20 anos em Belém, na atual Cisjordânia, morreu ali, aos 56 anos de idade, no ano 404.

A literatura de viagem se apresenta como "gênero híbrido" (TORRÃO FILHO, 2010, p. 50), posto que comporta influências, interferências e certo artesanato, i.e., a abertura à criatividade que permite sempre renovar-se, fazer de outro modo, dadas as circunstâncias e variáveis da época ou do local (ou voz) de onde parte a composição. Entretanto, mesmo aberta a tal artesanato, nem sempre consegue escapar ao que Torrão chamou "memória de biblioteca", que é refazer "o caminho de outros livros, nos passos dos viajantes e em sua escritura" (TORRÃO FILHO, 2010, p. 53), de modo que aquele que viaja repete, total ou parcialmente, um itinerário anterior, como os viajantes para a Espanha nos séculos XVIII e XIX, marcados que foram pela leitura de Quixote, de Cervantes (TORRÃO FILHO, 2010, p. 53).

A literatura de viagem exige atenção à qualidade da sua informação. Ela não constitui documento com total isenção. Não raro, os viajantes foram considerados mentirosos ou falsificadores, lançando mão do artifício retórico da persuasão por terem estado onde outros não estiveram (TORRÃO 
FILHO, 2010, p. 45-6). Há relatos compostos no conforto do lar, depois de decorrido algum tempo da viagem. Adams chamou a esses de "viajantes de lareira" ou "viajantes de gabinete". ${ }^{4}$ Houve quem partiu do dado concreto, mas imaginou cenários, dando com isso no campo da ficção (TORRÃO FILHO, 2010, p. 47). A esse respeito, Lisboa pontuou a diversidade da forma como se mostra tal literatura: "como diário de campo, cartas, relato, relatório científico, itinerário, relato de peregrinação; além de suas formas ficcionais, em prosa ou poesia ou mesmo as utopias e viagens imaginárias, por vezes apresentadas como reais" (LISBOA, 2011, p. 39).

Torrão Filho indicou um tripé que suporta as narrativas de viagem. Seguimos sua indicação. O tripé constitui-se da descrição, o conjunto das observações do autor, absorvidas do mundo e da natureza, que são "suporte e evidência concreta" a investigar. Em seguida, a interpretação, que é a tradução das observações a partir dos pressupostos e hipóteses contidos nas "teorias previamente estabelecidas que orientam a viagem”. Por fim, a transformação da viagem, que deixa de ser mero deslocamento para constituir etapa da apreensão do mundo com fins de desenvolvimento e progresso (TORRÃO FILHO, 2010, p. 43).

Uma pergunta que se coloca a esses relatos é que, considerando que muitos dos autores eram pessoas de fé cristã, foram movidos pela crença ou puderam ser exímios ou críticos nas descrições? Avaliamos cada caso em comparações com outros referentes obtidos de literatura mais aceita ou por comparação com textos do período coberto.

Feitas essas considerações iniciais, vejamos como se formou as duas tradições, a católico romana e a protestante evangélica, em torno de dois lugares distintos na cidade de Jerusalém.

\section{As duas histórias sobre os dois locais}

A queda de Jerusalém nas mãos dos romanos, no ano 70, e a demolição da cidade por Adriano, em 135, e a mudança de seu nome para Aelia Capitolina prorrogaram o retorno das peregrinações de judeus a Jerusalém para o século IV, quando foram autorizados a visitar as ruínas do Templo na cidade uma vez por ano (PARTIN, 1995, p. 18). Foi pelos cristãos e muçulmanos que a história das peregrinações para a região foi escrita. A partir da década de 30 , os cristãos foram rejeitados quando percebidos como um ramo do

4 Percy G. Adams. Travelers and trave liars 1660-1800. New ed. Nova York: Dover, 1980, p. 18, apud Torrão Filho, 2010, p. 47. 
judaísmo e expulsos por religiosos judeus por serem considerados agitadores religiosos. No ano 70 A.D., os romanos cercaram e, em seguida, invadiram Jerusalém e destruíram o Templo e tudo à sua volta. Os judeus que rejeitaram os primeiros cristãos foram expulsos pelas tropas romanas do General Tito e, por conseguinte, impedidos de visitar a principal cidade e centro da vida social e religiosa. Os cristãos foram mais rápidos em alcançar o favor do Imperador Constantino, cuja mãe, Flávia Júlia Helena (250-330), não só professou a fé cristã como patrocinou iniciativas que deram à cidade novo perfil arquitetônico. Aos favores de Helena são atribuídas a construção da “cúpula Anastasis (ou 'Ressurreição') sobre o alegado túmulo de Jesus e o Martyrium, uma basílica imediatamente a leste da Anastasis" (PARTIN, 1995, p. 18), ambas em Jerusalém.

O historiador Harry Partin especula sobre a possibilidade de ter havido peregrinações de cristãos nos primeiros séculos. A origem desses peregrinos teria sido a Galileia, Cesareia (na costa do Mediterrâneo) e Pella (na região da atual Jordânia), onde havia concentração de cristãos. Como não há registros confiáveis a esse respeito, não especularemos. O que é apontado pelo pesquisador do judaísmo antigo, S. Minouni, ${ }^{5}$ é que a partir da investigação de fontes literárias da Patrística (segundo ele, "difíceis de interpretar"), mas sem evidência arqueológica confiável, é que até no ano 135 houve a frequência de cristãos de origem judaica nas grutas onde se suspeitava ter sido colocado o corpo de Jesus Cristo.

Em 135, após a destruição de Jerusalém e a renomeação da cidade, Adriano construiu templos dedicados à tríade Júpiter, Juno e Minerva no local do Templo judeu; no ponto identificado como sendo a tumba de Jesus Cristo, ele construiu um templo em homenagem a Afrodite (MANSIR, 1999, p. 76). Joan Taylor (1993, p. 339), em pesquisa arqueológica, admite ter havido trânsito de peregrinos cristãos no final do século III, ${ }^{6}$ os quais procuravam pelos lugares simbólicos do nascimento, morte/sepultamento e ascensão de Jesus. Belém, Gólgota e a caverna de Eleona eram procurados pelos peregrinos, embora os sítios fossem utilizados por grupos vindos de diferentes partes do Império na realização de cultos pagãos.

\footnotetext{
Em Le judéo-christianisme ancien: Essais historiques. Paris, 1998, p. 364, apud Maraval, 2002, p. 65.

6 Smith (2007, p. 7) reporta o mesmo: que havia trânsito de peregrinos cristãos em Jerusalém e arredores antes do ano 315, conforme os escritos de Eusébio de Cesareia, Jerônimo e Alexandre da Capadócia.
} 
Se a evidência arqueológica diz pouco a esse respeito (como indica Joan Taylor), as fontes literárias parecem indicar que o bosque e a caverna próximos ao monte das Oliveiras foram anteriormente locais de culto a Tammuz-Adonis, e só depois apropriados pelos cristãos (TAYLOR, 1993, p. 339), que o adaptaram de acordo com sua crença. Segundo a autora, a tumba de $\mathrm{Maria}^{7}$ foi construída no século $\mathrm{V}$ e não tem raízes judaico-cristãs, dando a impressão de ter sido feita apenas para satisfazer as expectativas dos peregrinos acostumados a ouvir histórias apócrifas sobre a morte da mãe de Jesus.

\subsection{O peregrino anônimo de Bordeaux}

Há consenso que o início dos registros de viagens pela Terrae Sancta é a obra de um peregrino anônimo, supostamente cristão, vindo da região de Burdigala/Bordegala (Bordeaux, França), no século IV. Além das incursões militares feitas pelos romanos, as viagens a Jerusalém no início da presente era tinham caráter religioso; Jerusalém não tinha atrativos, não era produtora de bens, nem militarmente avançada, não tinha uma população politicamente ativa e não ficava entre as rotas principais do comércio internacional (PARTIN, 1995, p. 16).

A intensificação das viagens para lá ocorreu dois séculos após as primeiras conversões cristãs pelos pagãos no Império Romano. Os armênios se cristianizaram antes disso, mas não há registros de terem sido os primeiros peregrinos para os locais sagrados do cristianismo. Certamente a adesão dos romanos à nova religião provocou nos fiéis o desejo de conhecer o território onde o seu Salvador nasceu, viveu e morreu, e como diz o dogma, ressuscitou.

O Itinerarium Burdigalense ("Itinerário de Bordeaux"), ${ }^{8}$ também conhecido como o Itinerarium Hierosolymitanum, é o mais antigo itinerário cristão conhecido e foi escrito na França (HUNT, 2003). Ele relata a viagem do escritor entre os anos de 333 e 334 (ELSNER, 2000), enquanto viajava por terra, cruzando o norte da Itália e o Danúbio rumo a Constantinopla, avançando pela Ásia Menor e Síria, até chegar a Jerusalém. Nas margens do relato ele dá informações superficiais sobre cada cidade por onde passou.

\footnotetext{
7 Taylor especifica a Church of Mount Zion, mas não diz que se trata da "Dormition" nem se ela fica no Mt. Zion. Há outras igrejas que homenageiam a Morte de Maria, até mesmo nos Estados Unidos.

8 O texto chegou aos nossos dias em quatro manuscritos, copiados entre os séculos VIII e X. A primeira versão impressa data do século XVI e a última data do século XIX.
} 
Após registrar cada ponto de deslocamento e pouso, concentrou-se no que viu em Jerusalém. É desproporcional a atenção dada aos monumentos judaicos, o templo e os edifícios de Salomão, e nem tanto a igrejas e basílicas. Ele as menciona, mas com menos ênfase. Como nos informa, tais edifícios foram construídos por ordem do Imperador Constantino, como a Igreja do Santo Sepulcro e, ao pé do monte das Oliveiras, a Catedral das Nações.

Tanto a Igreja do Monte Sião, a Igreja da Natividade, em Belém, a Igreja do Santo Sepulcro como a Catedral das Nações, foram construídas por Constantino para comemorar quatro eventos conectados à tradição cristã. Eles são: o dogma da pré-encarnação do Cristo, cuja aparição a Abraão se deu na região de Mamre (no bosque de carvalhos de Mamre, Hebrom), o seu nascimento em Belém, a morte e a ressurreição no Gólgota e a ascensão no monte das Oliveiras (TAYLOR, 1993, p. 307). Conforme Eusébio, em Vita Constantini, Helena, a mãe do Imperador e Eutrópia, a sua sogra, se empenharam em identificar os lugares dos acontecimentos para que os edifícios fossem construídos e, assim, atrair a peregrinação dos cristãos.

Helena foi encarregada de vasculhar a região de Belém e do monte das Oliveiras e Eutrópia cuidou de Mamre. Era um programa constantiniano de erradicação do paganismo em favor da cristianização do império (TAYLOR, 1993, p. 339). O próprio Constantino esperava poder peregrinar na região (Eusebio, Vita Const. ii. 72.2) e desejava ser batizado no rio Jordão (Eusebio, Vita Const. iv. 62. 2) (TAYLOR, 1993, p. 308), o que nunca ocorreu.

Jaś Elsner, comentando o Itinerarium, deixou transparecer surpresa ao constatar que apenas 21 anos depois de Constantino institucionalizar o cristianismo no império, os principais locais na antiga Jerusalém tinham sido descaracterizados em relação à ação de Adriano, que tinha desfigurado a cidade para refundá-la, em 131, ${ }^{2}$ como Aelia Capitolina (ELSNER, 2000, p. 181). Essa geografia da cidade pode ser resgatada pelo Itinerarium que, embora tenha recebido críticas em pontos de sua narrativa, ${ }^{10}$ dá detalhes para o entendimento da nova topografia e a comparação com relatos anteriores e posteriores, além de contribuir com o entendimento sobre a ação política dos próprios imperadores interferindo na arquitetura local.

A contribuição dos itinerários para o entendimento da cartografia é certa. Houve um programa imperial para a construção de catedrais e entre as primeiras dessas estruturas, no início do século IV, está a Igreja do Santo

\footnotetext{
$9 \quad$ Partin (1995, p. 18) datou em 131.

10 E.g., Laurie Douglass, A New Look at the Itinerarium Burdigalense. In: Journal of Early

Christian Studies, v. 4, n. 3, Fall 1996, p. 313-333.
} 
Sepulcro, de tradição católica. A localização constante da topografia local independe, como observado, da fé nos relatos consultados até aqui.

\subsection{General Gordon, o militar inglês inconformado com os católicos (1883)}

A origem da nova tradição entre os protestantes evangélicos, rejeitando o local tradicional para o Santo Sepulcro, conforme os católicos admitiam, tem raízes no século XIX. De abril de 1881 a abril de 1882, o General Charles George Gordon, Comandante dos Royal Engineers (um dos corpos do Exército Britânico) nas ilhas Maurício (Oceano Índico), ${ }^{11}$ foi incomodado com a ideia de localizar o Jardim do Éden. Em novembro de 1882, voltando para a Inglaterra, rejeitou o convite do rei Leopoldo II para assumir o comando do Congo belga.

O General Gordon deixou a Inglaterra para um período de descanso e estudos no Norte da África. Passando pela Terra Santa, fez explorações geográficas de sítios religiosos, seguindo o entendimento do protestante inglês tradicional, e trocou cartas com Sir John Cowell, da controladoria da família da Rainha Victória. Gordon reportou suas suspeitas e descobertas a respeito do que considerou a verdadeira localização do histórico sepulcro (MERYON, 2012, p. 3). O folclore acerca da rejeição do antigo local se construiu em torno da questão da grande quantidade de imagens e adereços cúlticos na Igreja do Santo Sepulcro. A partir da Reforma no século XVI a tradição protestante rejeitou os objetos da tradição católica, de modo que o General Gordon teria se sentido incomodado de que o seu Salvador tivesse sido sepultado num local como aquele, onde uma prática religiosa reprovável para ele se desenvolveu (Foto 7).

Tendo encontrado uma formação geológica adjacente ao monte Moriá, em Jerusalém, com "uma clara imagem de enorme crânio humano na face da rocha" (MERYON, 2012, p. VII; tradução do autor) se convenceu, e também a outros até hoje, de que havia descoberto o verdadeiro local da crucificação. Até julho de 1883, quando partiu da região pelo porto de Jafa, o General Gordon visitou, desenhou, fez anotações, analisou e escreveu oito cartas (é possível haver mais, pois algumas estão sem data) a um soldado amigo chamado Sir John Cowell. ${ }^{12}$

\footnotetext{
11 O General Gordon (1833-1885), também conhecido como Gordon Paxá ou Gordon Chinês, fez campanhas pela China e África. Nasceu em Londres, em 1833, e foi assassinado em Cartum, em 1885, um ano após deixar Jerusalém.

12 As datas das cartas são: 15.11.1882, 18.01.1883, 20.01.1883, 5.03.1883, 8.03.1883, 20.03.1883, 27.04.1883, 7.05.1883, 25.05.1883, e uma para sua irmã escrita em 18.01.1883.
} 
Em carta trocada com sua irmã, em 18 de janeiro de 1883, Gordon afirmou "sentir-se convencido de que a colina próxima ao Portão de Damasco é o Gólgota" (MERYON, 2012, p. 6; tradução do autor). Da colina foi possível ver o monte do Templo e "bastante poças de sangue [...] ali", e que (aqui ele não foi específico) "está coberto com túmulos de muçulmanos; há muitas cavernas rochosas; e jardins que o cercam" (MERYON, 2012, p. 6; tradução do autor). ${ }^{13}$

A descoberta do suposto sítio do (novo?) Santo Sepulcro, no monte Caveira (ou Gólgota), pode ser posta sob suspeita por uma série de motivos, mas é inegável a influência que teve no desenvolvimento do turismo e na mobilização de peregrinos até hoje, dividindo o interesse, os itinerários e as receitas advindas do turismo, entre cristãos católicos e evangélicos, e ações pontuais de muçulmanos em sua panfletagem religiosa. ${ }^{14}$ Os católicos visitam a Igreja do Santo Sepulcro na cidade velha de Jerusalém, desde os dias de Helena (anterioridade que por si é argumento forte em favor da tradição católica); os evangélicos vão um pouco além (menos de um quilômetro), onde tem funcionado o protetorado britânico que controla o sítio onde o General Gordon identificou, como relatado nas cartas trocadas com Cowell em 1883, o Gólgota, o horto, o imenso reservatório de água, o lagar (veja a seguir) e uma tumba escavada na rocha, tal como indicam os textos cristãos do Novo Testamento, como creem os evangélicos.

As fotos mostram os fundos de um cemitério muçulmano visto de dentro do Calvário de Gordon, cujo muro está acima do que Gordon identificou como a rocha parecida com caveira. A Foto 3, à esquerda, foi tirada em 2011 e dá a atual aparência do rochedo, enquanto à direita está a reprodução de uma imagem feita no início do século XX.

$13[\ldots]$ quite pools of blood are lying there. It is covered with tombs of Muslim; there are many rock-hewn caves; anda gardens surrounding it.

14 Entre os anos de 2011 e 2012, a administração de um cemitério para muçulmanos em Jerusalém pintou no lado dos muros: "Alá é o único Deus e ele não tem um filho". A inscrição pode ser lida por peregrinos cristãos em visita ao Calvário de Gordon. 
Foto 1. Fundos do cemitério muçulmano visto do Calvário de Gordon (Jerusalém), onde se lê "La ilah illa llah muhammadan rasulu allah" (a shahada, ${ }^{15}$ placa maior) e "Cemitério mujahedin islâmico" (outra).

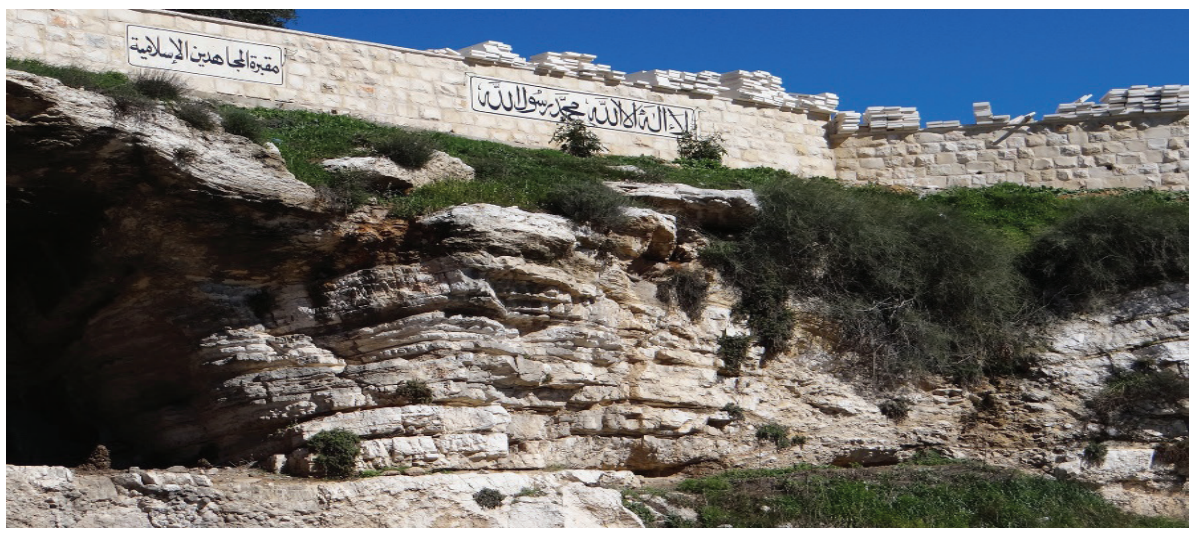

Foto 2. Portão de Damasco hoje. Saída da cidade para o Calvário de Gordon (arquivo pessoal do autor).

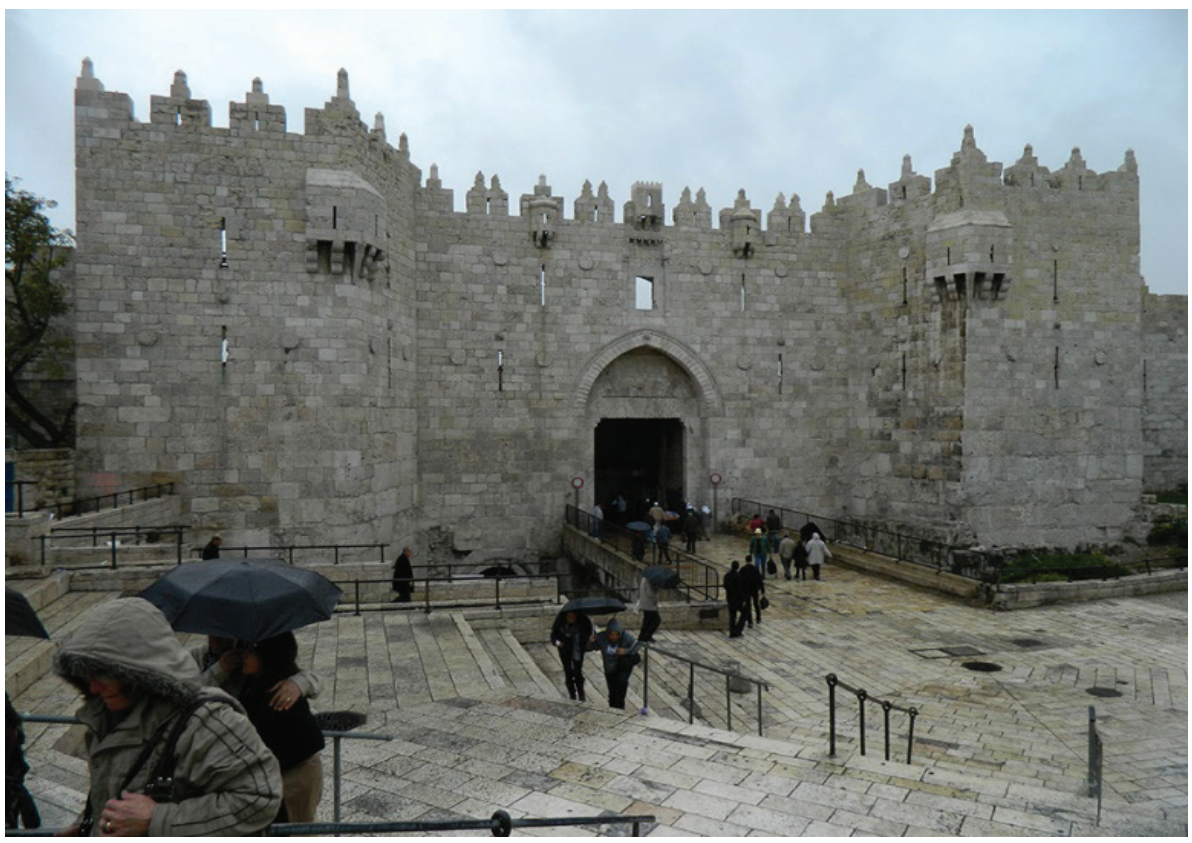

15 A shahada é a confissão de fé que quer dizer "testemunho que não há divindade além de Deus, e testemunho que Muhamad é seu profeta". 
Foto 3. Monte Caveira (Gólgota) hoje e reprodução de foto exposta pelo The Garden Tomb (Jerusalém) (arquivo pessoal do autor).

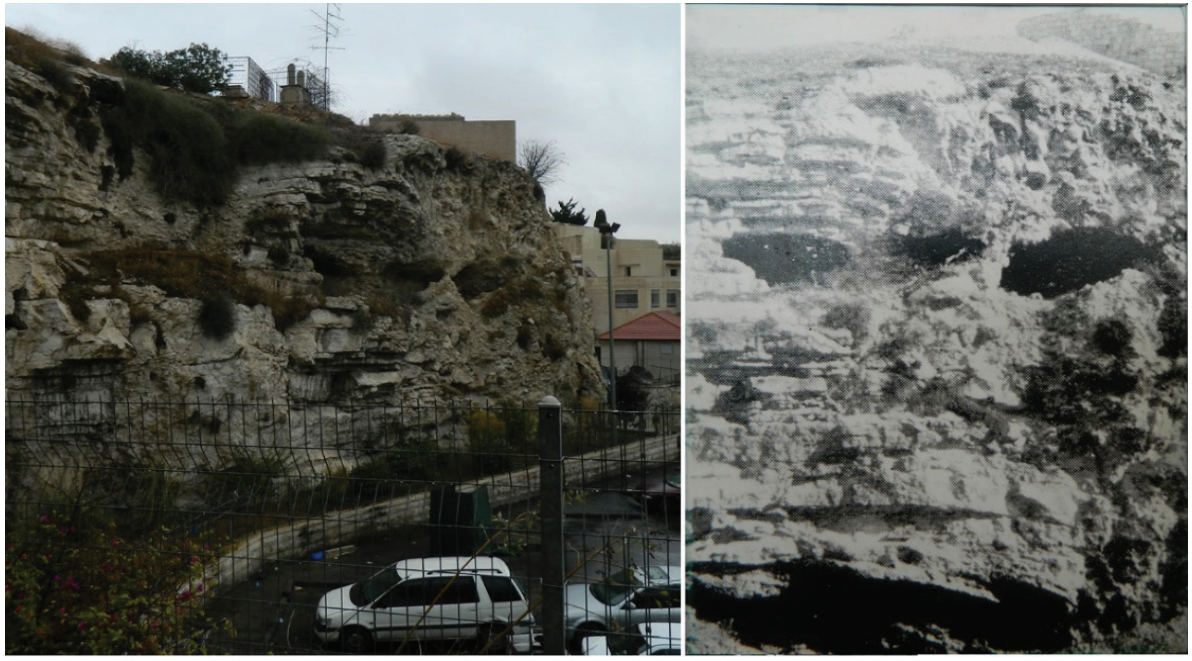

Fotos 4 a 6. À esquerda, local do Horto onde havia uma prensa de uvas; ao centro, entrada do reservatório de água necessária para a atividade agrícola do horto e, à direita, foto exposta no local tirada dentro do imenso reservatório (arquivo pessoal do autor).
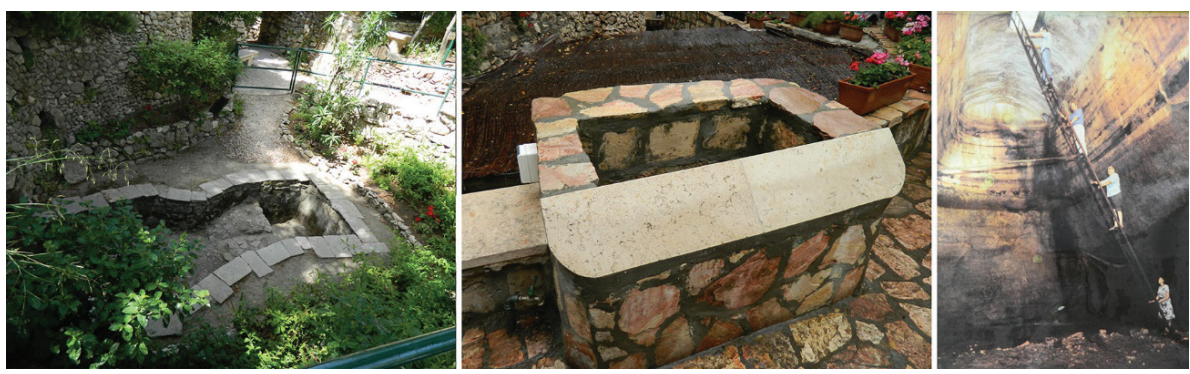

Para associar o local ao que se lê nos Evangelhos, o protetorado dispõe publicamente as Fotos 4 a 6, que demonstram ter sido ali o local onde se espremiam uvas, um horto, vinculando a ideia do esmagamento da uva para fazer vinho ao sofrimento de Jesus em favor dos pecadores, conforme a crença cristã. Admitindo a descrição feita pelo General Gordon, gradualmente os grupos protestantes migraram seu destino turístico para esse novo local, como fazem até hoje, divergindo dos católicos. A seguir, verificaremos o que mais pode ter acontecido na topografia urbana em Jerusalém que permita arbitrar em favor de uma ou de outra tradição. 
Foto 7. Altar no interior da Igreja do Santo Sepulcro, com objetos de culto rejeitados pelos protestantes.

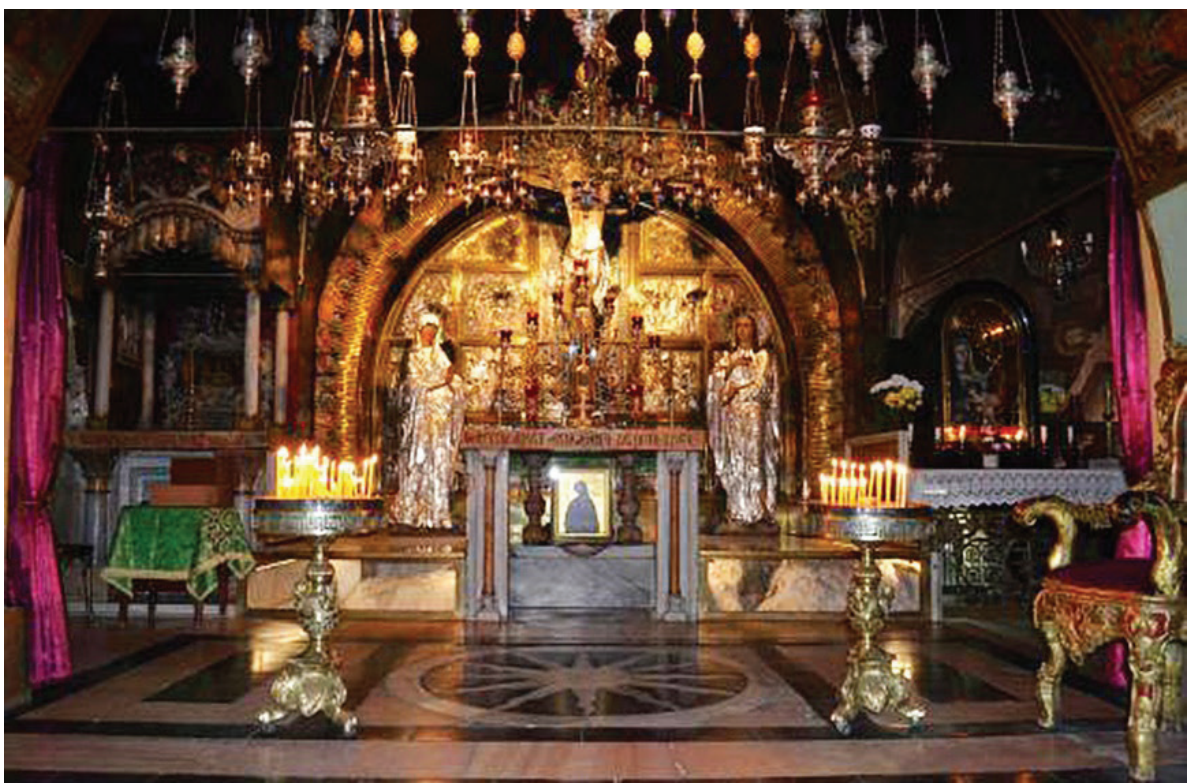

Foto: Eliceli Katia Bonan.

\section{Desfazendo o mal-entendido}

Tendo disposto as narrativas que apoiam locais distintos para o milenar túmulo onde o corpo de Jesus teria sido sepultado, vejamos as narrativas de viagens posteriores ao período Constantiniano e qual local mencionado elas apoiam como sendo o legítimo. A leitura das próximas fontes foi realizada durante nossa pesquisa de doutoramento, concluída em 2018. ${ }^{16}$

\subsection{Paula e sua filha Eustáquia}

Combinam com a informação dada por Pierre Maraval os detalhes de uma carta enviada por Paula (382 A.D.), que vivia em Roma (WILSON, 1889) à destinatária Marcella. Paula havia sido uma matrona rica da alta sociedade romana, sendo servida por eunucos (JEROME, 1887, p. iv), em uma família nobre de longa ascendência. Ela foi profundamente tocada pela mensagem de Jerônimo de Estridão (347-420 A.D.), teólogo e historiador da igreja.

16 A bistória recente do turismo religioso brasileiro e seu papel no conflito Israel-Palestina. Tese de Doutoramento em História Social apresentada ao Departamento de História da Universidade de São Paulo (FFLCH-USP). São Paulo, 2018 (ver especialmente capítulos 3 e 4). 
Quando decidiu abandonar os prazeres da vida que levava no centro do império, tornou-se fervorosa discípula de Jesus, com sua filha Eustáquia, de quem é dito ter sido a primeira jovem a fazer votos de castidade (WILSON, 1889 , p. i). Decidida a enfrentar os perigos que uma viagem ao Norte da África e à Palestina reservavam, partiu rumo ao deserto. ${ }^{17}$

As descrições geográficas que Paula deu são superficiais, embora confirmem a existência de um local destinado a reuniões dos fiéis no período. Sua carta revela o que, afinal, chamaria a atenção de uma mulher devota, rica e abastada da alta sociedade romana na época. A carta a Marcella, também rica dos mesmos círculos sociais de Paula, ${ }^{18}$ também fala da veneração à cruz (como Etéria), a tumba e a pedra que lacrou o sepulcro de Jesus, a Igreja do Monte Sião, além da coluna do flagelo (v. Antoninus Mártir) e o Cenáculo (WILSON, 1889, p. i), que pode ser visitado, local da última ceia e do evento de Pentecostes, conforme o Livro de Atos.

\subsection{O relato de Antoninus Martyr}

O ambíguo relato do itinerário dos lugares visitados por Antoninus (WILSON, 1887) tem sido datado do início do século VI (500-530 A.D.). Sobre o peregrino pouco se sabe, além de que era original da Placentia, Itália. As menções feitas a ele dão o adjetivo de mártir, mas nada é dito sobre o martírio. Wilson (1887, p. iii) acredita ter sido um sacerdote, mas o apresentou como "ignorante e supersticioso". Há razões de sobra para isso, conforme o texto.

O roteiro percorrido é confuso e por vezes desconexo. Em determinados pontos falta a coerência interna que se espera de um viajante que está atento à ordem geral, tal quando se faz um diário de bordo, como em outros itinerários consultados. A descrição dos lugares é inverossímil, cheia de erros "facilmente detectados", "possivelmente adicionados no oitavo ou nono século" (WILSON, 1887, p. v). "Antoninus não é a testemunha mais confiável”, sentencia Baruch Halpern, arqueólogo e professor de Estudos Judaicos. Comparando com o itinerário de Paula, Antoninus indica a existência

\footnotetext{
17 A Introdução de Wilson diz “a journey to St. Paul and Anthony in the desert" (WILSON, 1889, p. ii). Sabe-se, hoje, da existência de um monastério de St. Paul, no deserto, na região do Egito. Jerônimo diz que Antônio e Paulo viveram no deserto.

18 Notamos a forte influência social de ambas no fato de o Procônsul de Jerusalém ter ordenado ao Pretório que oferecesse os melhores aposentos a Paula, ao que ela declinou em função do "verdadeiro espírito da peregrinação".
} 
de uma fonte de água em Kafr Kanna, em desacordo com a informação dada pela peregrina, "que vê (Kafr) Cana de Nazaré" (HALPERN, 2006, p. 215).

A respeito do aspecto supersticioso do autor, notamos o encantamento que sentiu, como em Etéria, pela holy cross, ${ }^{19}$ a cruz que Helena alegou ter encontrado, e o momento quando era apresentada durante as celebrações. O peregrino disse que quando a cruz era trazida da câmara no interior do átrio da igreja para ser adorada e beijada, na mesma hora surgia uma estrela no céu e se punha acima do local onde a cruz era apoiada. Enquanto a adoração ocorria, com a estrela no alto (não sabemos como foi possível notá-la de dentro da igreja), pequenas quantidades de óleo em frascos eram aproximadas da cruz para que recebessem dela o seu poder. Então o óleo fervia, chegando a borbulhar. "Quando a cruz é levada de volta para o seu lugar, a estrela também desaparece” (WILSON, 1887, p. 17). Não há descrição sobre a qual "basílica de Constantino" Antoninus se referia. Diz ser próxima ao Gólgota, podendo ser a Igreja do Santo Sepulcro, mas isso não é certo.

\subsection{Willibald, o monge alemão}

Willibald, ${ }^{20}$ um monge cristão que se tornaria bispo de Eichstadt (e após a sua morte "São Willibald"), é considerado o primeiro alemão a peregrinar na Terra Santa (BENSINGER, 1971, p. 1), cerca do ano 754. Ele era sobrinho de "São Bonifácio, o apóstolo da Germânia" (WILLIBALD, 1895 , p. vii) por parte de mãe. Duas histórias a seu respeito chegaram a nós. Uma delas é o Hodoeporicon (gr. itinerário ou jornada), escrito por um diácono que fez as anotações a partir das memórias do próprio bispo. A outra, IItinerarium $S$. Willibaldi, foi escrita por uma freira da abadia de Heidenheim, um mosteiro fundado por Bonifácio, o tio.

Tendo percorrido algumas regiões conhecidas na Itália (Roma, Nápoles, Monte Etna, Siracusa e outras), Willibald navegou pelo Adriático, tendo passado por Monenvasia, Chios, Samos, Éfeso, Hierápolis, Patara, Mileto, Chipre, Pafos, Constantia, Damasco, Emesa (atual Homs, Síria) e, finalmente, Caná e Monte Tabor, os primeiros pontos geográficos na Palestina.

\footnotetext{
19 A espanhola Etéria, uma dama letrada, aristocrata e com dinheiro, chamou a cruz de True Cross. Às Sextas-feiras da Paixão, a Cruz Verdadeira (the True Cross), descoberta por Helena, mãe do imperador, era venerada. Carlos Pascual. Egeria, la Dama Peregrina. Arbor CLXXX: 711-712; 451-464, mar./abr. 2005, p. 458.

20 O IItinerarium $S$. Willibaldi é o único relato proveniente do século VIII.
} 
O IItinerarium ordena as localidades por onde Willibald passou, ${ }^{21}$ mas sem acrescentar informações relevantes sobre a geografia, a arquitetura e as populações. Restringe-se a fazer associações comuns com passagens das Escrituras cristãs e hebreias e, quando muito, alguma curiosidade trivial. Parece mais realista que outros relatos, não constando milagres nem superstições aparentes.

Quando Willibald e seu irmão chegaram a Jerusalém, diz-se que foram ao lugar onde a "Cruz Sagrada" foi encontrada por Helena. Havia uma igreja no local onde era considerado o Calvário e aqui a surpresa: o texto diz que esse lugar, "antigamente ficava fora de Jerusalém, e que quando Helena encontrou a cruz, providenciou que o lugar fosse arranjado de modo a que ficasse dentro da cidade de Jerusalém" (WILLIBALD, 1895, p. 19, grifo do autor), talvez temendo ataques de estrangeiros. Esse arranjo feito por Helena é curioso, porque o Novo Testamento diz que Jesus foi crucificado "fora das portas da cidade" (Hebreus 13.12). Mudar o local do sepultamento deporia contra as narrativas do Novo Testamento e da tradição cristã.

Willibald descreveu a aparência do sepulcro: foi escavado na pedra, acima do solo, sendo a base quadrada e a parte superior afunilada. Evidentemente, há uma cruz nas proximidades e uma "casa maravilhosa", com uma porta para o interior do sepulcro, onde as pessoas entram para fazer suas orações. No lado de fora, uma réplica da pedra que era usada para lacrar a sepultura segundo o costume dos judeus (v. Evang. Mateus 27.60).

Após visitar outros pontos, Willibald encerrou o que seria o período de maior presença do interesse cristão nos pontos geográficos e arquitetônicos na Palestina. Por ser um religioso, seu itinerário praticamente não se compara ao Itinerarium Burdigalense. Não notamos informações que atualizassem dados sobre as populações e costumes, política ou economia. Do ponto de vista da tradição religiosa ele é rico, embora sejam questionáveis as declarações registradas por aqueles que tomaram as notas de suas memórias. Ficamos ansiosos por mais dados que pudessem nos informar, por exemplo, acerca do acirramento das relações com os árabes, que a essa altura já ampliavam o seu domínio na região de maneira ostensiva.

21 Tibérias, Magdalena, Cafarnaum, Betsaida, Corazim, "Jor and Dan, the Jordan", os tanques de Merom, Cesarea de Filipe, o Monastério e a Igreja de S. João Batista, uma Festa da Epifania, Galgala (?), Jericó, o Monastério de S. Euthymius (descrito por Antoninus como Kusr el-Yehûd). Em Jerusalém, a igreja e as cruzes no local chamado Calvário (Monte?), o jardim com o sepulcro de Jesus e a "casa maravilhosa". 


\subsection{Seawulf}

A história atribuída a esse peregrino data de julho de 1102 a setembro de 1103. É dito ter sido anglo-saxão e sua narrativa parece a única que sobreviveu ao período após os cruzados conquistarem Jerusalém. Seawulf foi um monge ou abade cristão. Há historiadores que o identificam como um merchan britânico (GARNETT, 2000, p. 1). O tradutor da obra diz não ser possível afirmar que fosse um clérigo ou jurista e garantiu ser um homem piedoso (SAEWULF, 1892, p. viii). O seu nome é incerto; pode ser "nome de guerra", como "sea dog", já que "wulf” era uma terminação comum para nomes britânicos (SAEWULF, 1892, p. vii).

$\mathrm{O}$ autor do itinerário observou algo relevante para os peregrinos. Os Evangelhos dizem que Jesus foi sepultado numa pedra escavada (Lucas 23.53), num horto, fora da cidade. Adriano, em 135, fez reformas e mudanças em Jerusalém e no Templo. Seawulf confirma a informação de que Adriano "estendeu a cidade, tanto quanto a Torre de David, que anteriormente tinha alguma distância da cidade". Ele notou ser possível "ver do monte das Oliveiras, [como] eram as paredes [no] extremo Oeste da cidade antigamente e quanto a cidade foi, mais tarde, estendida" (SAEWULF, 1892, p. 10; tradução do autor). ${ }^{22}$ Fazendo isso, os locais da morte e do sepultamento de Jesus passaram para dentro dos muros da cidade (Figura 1) como diz o Novo Testamento, não mais fora, como Willibald deixou entrever em seu relato.

A questão não foi observada pelo General Gordon nem pelos evangélicos. A tradição católica não discute a questão, mesmo que ao longo dos séculos a Igreja do Santo Sepulcro tenha sofrido reformas na estrutura.

\subsection{Citez de Jherusalem}

Uma notável destruição das igrejas e, aparentemente, das demais edificações na cidade de Jerusalém surge em uma narrativa anônima do século XIII, publicada em francês antigo sob o título Citez. de Jherusalem. Fala da conquista de Jerusalém por Saladino em 1187 A.D., e foi escrita, provavelmente, em 1220 (CONDER, 1896, do prefácio). O autor deixa transparecer a dificuldade em identificar os locais onde as igrejas deveriam estar, dizendo haver uma abadia nas imediações do monte das Oliveiras e que Jerusalém não ficava muito longe de onde estava. A razão da destruição

22 E acrescenta: "O imperador chamou a cidade pelo seu próprio nome, Aelia, que significa a Casa de Deus". Não há confirmação sobre a fonte dessa tradução feita por ele, nem se havia registros do imperador. 
também foi dada: Saladino e os sarracenos tomaram Jerusalém e modificaram sua paisagem em relação a antigos itinerários que o peregrino pode ter usado como guia (CONDER, 1896, p. 1-2). Na ocasião, Jerusalém estava sob o protetorado cristão e o Domo da Rocha, e.g., era usado como igreja e chamado de Templum Domini (CONDER, 1896, p. 13).

Figura 1. O Calvário (Traditional Calvary) localizado fora dos muros nos tempos de Jesus, cf. Novo Testamento. Após a ampliação feita por Adriano (Hadrian's Wall), o local passa a figurar dentro da cidade velha até hoje.

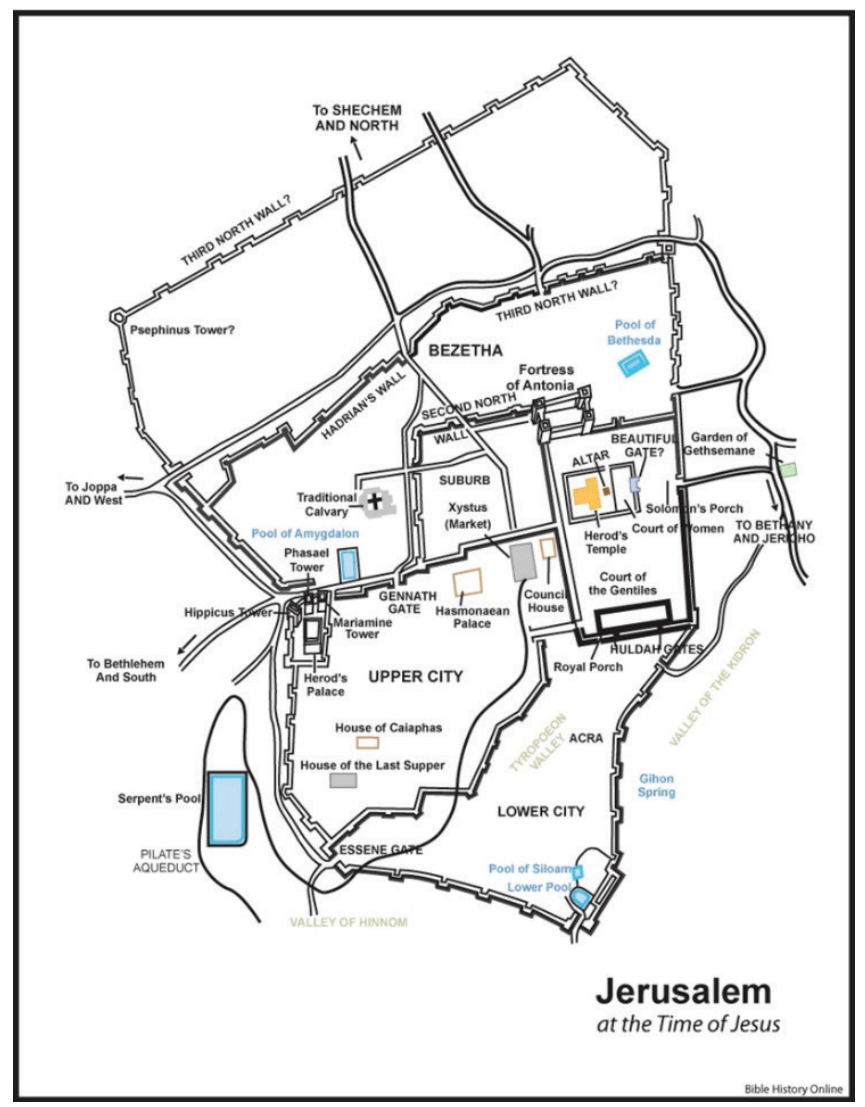

Embora não mencione ser um religioso, o autor de Citez de Jherusalem pareceu ter recebido permissão para entrar a áreas dos templos e dos edifícios e dar melhor detalhamento dos seus ambientes internos. Descreveu o sepulcro de Jesus e a igreja de Santa Helena, onde escreveu que Helena "encontrou a 
cruz, os pregos, o martelo e a coroa [de espinhos posta em Jesus]", saiu para uma rua chamada Mal-quisinat. ${ }^{23}$ "Nesta rua os alimentos eram cozidos e vendidos para os peregrinos, e eles lavavam as suas cabeças. Dali eles partiam para o Sepulcro" (CONDER, 1896, p. 11). Um comércio de alimentos, e mais que isso, também de animais, se estabeleceu em função do ponto de encontro dos peregrinos, a ponto de Conder chamar o local de Exchange. ${ }^{24}$ Depois do empenho de Constantino em demarcar com construções os pontos de interesse para a peregrinação cristã, essa é a primeira vez que uma atividade comercial aparece relacionada às viagens feitas por religiosos a Jerusalém.

Aparentemente, o comércio estava nas mãos dos sarracenos (árabes). Eram eles que permitiam aos cristãos visitarem o Sepulcro de Jesus dentro da Basílica, acessado por uma rua lateral, não pela rua principal. A visitação era discreta, sempre pagando por isso: serviços, presente e dinheiro, pago em trinta bezants, uma moeda de ouro cunhada no Império Bizantino. Isso não durou muito tempo, pois logo os cristãos foram excomungados (não deixou claro por quem), e os sarracenos não puderam mais lucrar com o negócio (CONDER, 1896, p. 16). O que permaneceu parece ter sido uma característica ainda observável: o comércio localizado e a divisão da cidade por bairros. O que chamamos "cidade velha" está dividida em bairros, ${ }^{25}$ e já naqueles dias as ruas eram identificadas pela etnia: "Aqui morava a maioria dos sírios de Jerusalém, e as ruas eram chamadas judaicas", e também fala de "ruas latinas", isto é, onde estavam os monastérios e igrejas dessa tradição (CONDER, 1896, p. 25,28).

Embora o autor (Philippus Brusserius Savonensis, c. 1350 A.D.) não tivesse um critério historiográfico, nem esperamos que tivesse, fez descrições de prédios e locais importantes, como os demais roteiros, e procurou demonstrar interesse pela história sem se distanciar das descrições bíblicas, que para ele eram a base de suas afirmações. Sobre Jerusalém, comentou os nomes que a cidade recebeu: primeiro ela foi chamada de Jebus, depois Salém. Esses deram origem ao terceiro, Jerusalém. Então ela veio a ser chamada Hierosolima, Solima, Luz, Betel. Por último, Aelia, quando foi reconstruída e rebatizada por Adriano (BERNARD, 1894, p. 4,5).

\footnotetext{
23 Mal-quisinat é uma forma francesa e irônica para "má cozinha", "má alimentação".

24 "I will come back to the Exchange. Before the Exchange ..." indica haver um local determinado para o comércio.

25 Os bairros são: judeu, armênio, muçulmano e cristão. A área do Templo, hoje com a mesquita, completa a composição da cidade velha.
} 


\subsection{John Poloner}

O itinerário de John Poloner (c. 1421 A.D.) foi escrito a partir de uma detalhada observação, a despeito de suas crendices religiosas, e veio acompanhado de um mapa em que dividia a região em quadras, a fim de ajudar a localização dos pontos e facilitar a composição do próprio desenho. Ele diz que "a Palestina que é propriamente chamada Galileia ... está na quadra 37 ... sobre uma colina que no mapa eu tenho pintado de verde. [...] Samaria ... na quadra 53. [...] Eu tenho pintado a Judeia, seu campo e colinas de amarelo" (POLONER, 1894, p. 24).

Igrejas, conventos e monastérios na Terra Santa exercem fascínio nas pessoas de fé a ponto de os peregrinos prepararem esboços ou rascunhos, especialmente da Igreja do Santo Sepulcro, a fim de levá-los para a Europa, ou onde quer que morassem. Os viajantes os apresentavam às autoridades para que fossem reproduzidas em suas terras a arquitetura original dos edifícios (ARAD, 2014, p. 2). Era a tentativa de aproximar, pela produção idêntica das catedrais originais, atribuía sacralidade ao novo edifício e conferia maior autoridade religiosa. Mas com a eclosão da Reforma Protestante, as peregrinações tiveram seu ímpeto diminuído.

O artigo de Pnina Arad dá a ideia do hábito de construir edifícios religiosos na Europa a partir dos modelos visitados na Palestina. William Wey, sacerdote e teólogo no Eton College, na Inglaterra, recebeu permissão de Henrique VI para peregrinar pela Terra Santa, em 1457. Após o retorno, ele construiu uma pequena capela no monastério de Edington a partir de memórias que guardava da Igreja do Santo Sepulcro (ARAD, 2014, p. 307-316).

Com a última descrição, acreditamos ter reunido os relatos de viagem mais relevantes segundo a historiografia do período de aproximadamente mil anos, desde o surgimento do primeiro texto, do peregrino anônimo de Bordeaux.

\section{Considerações finais}

A esta altura, estamos seguros de que a revisão bibliográfica, com os conteúdos narrativos das viagens, a história das transformações arquitetônicas da cidade, bem como, alguns indícios que a arqueologia tem apresentado, dão indicação segura para afirmarmos que a tradição católica é mais acertada que a evangélica em determinar a Igreja do Santo Sepulcro como o local mais confiável para ser associado aos eventos da crucificação e sepultamento de Jesus. Além desses indícios, ainda é possível verificar pela situação topográfica da Igreja do Santo Sepulcro, que a tradição católica é mais consistente, como a Figura 2 pode esclarecer. 
Figura 2. Corte lateral da Igreja do Santo Sepulcro, que recobre o sítio onde estariam o sepulcro e o Gólgota.

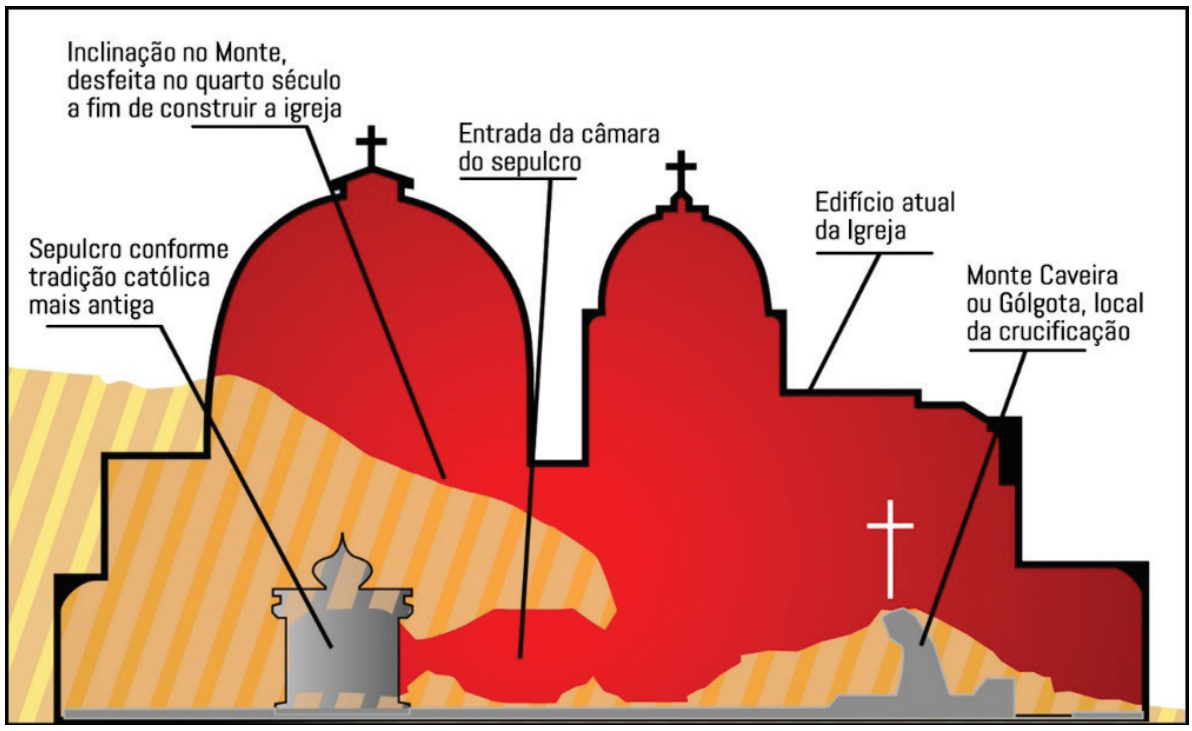

A Figura 2 apresenta o corte lateral do edifício da Igreja do Santo Sepulcro, construída sobre os sítios arqueológicos do sepulcro e do Gólgota, que segundo a tradição ocorreram o sepultamento e a crucificação de Jesus, respectivamente. Apesar do incômodo do General Gordon ao se deparar com um ambiente alienado de suas convicções dogmáticas e, inconformado com a situação, ter considerado a possibilidade de que haveria outro local para apoiar a sua fé, consideramos mais seguro concentrar a atenção na geografia católica por sua anterioridade, depois das evidências colhidas na revisão bibliográfica que exibimos.

Certamente, ao lidar com objetos da fé, independentemente de qual tradição se trate, sempre haverá fiéis que rejeitarão as evidências em contrário. Contra isso, não podemos construir argumentos, senão lidar dentro dos parâmetros da fenomenologia, o que não é nossa proposta. Nos limites das evidências apresentadas, tudo aponta para o antigo local da igreja construída ainda nos tempos do Império Romano, tendo sido o local identificado por Helena, mãe do Imperador Constantino. É sabido que a edificação passou por várias reformas por conta do tempo e terremoto, mas a localização não tem sido removida de dentro dos muros da antiga cidade de Jerusalém. Se o General Gordon não considerou a ampliação dos muros, fosse a pedido de 
Helena, ou anteriormente por Adriano no século II, novamente a questão foge do que se pode demonstrar historicamente.

\section{Referências}

ARAD, P. 'As If You Were There': The Cultural Impact of Two Pilgrims' Maps of the Holy Land. In: Visual Constructs of Jerusalem, ed. Bianca Kühnel, Galit NogaBanai, Hanna Vorholt. Turnhout: Brepols, 2014, p. 307-316.

BENSINGER, G. J. Palestine in German Thought and Action 1871-1914 (1971). Dissertations. Paper 1162. Disponível em: http://ecommons.luc.edu/luc_diss/1162 e acessado em: 21.01.2017.

BERNARD, J. H. (trad.). Guide Book to Palestine (Circ. A.D. 1350). London: Palestine Pilgrims Text Society, 1894.

CONDER, C. R. City of Jerusalem (1220 A.D.). Trad. from the Old French with notes by C. R. Conder. London, 1896.

ELSNER, J. The Itinerarium Burdigalense: Politics and Salvation in the Geography of Constantine's Empire. The Journal of Roman Studies, v. 90 (2000), p. 181-195. New York: Society for the Promotion Published of Roman Studies.

GARNETT, M. E. The longed-for place, Seawulf and twelfth-century pilgrimage to the Holy Land. Williamsburg, Virginia, 2000.

HALPERN, B. The miraculous wine of Cana in its Galilean Ceramic Context. In: Confronting the Past: Archaeological and Historical Essays on Ancient Israel in Honor of William G. Dever; Seymour Gitin, J. Wright and J. P. Dessel (Orgs.). Winona Lake, Indiana: Eisenbrauns, 2006.

HUNT, E. D. Holy Land Pilgrimage in the Late Roman Empire AD 312-460. Washington: Dumbarton Oaks, 2003.

ISRAEL, Tourist Information. Visitors \& Tourists Arrivals 2017. Ministry of Tourism, 2017.

JEROME, St. The Pilgrimage of the Holy Paula, trad. Aubrey Stewart. London: Palestine Pilgrims' Text Society, 1887.

LISBOA, K. M. Mundo novo, mesmo mundo; viajantes de língua alemã no Brasil (1893-1942). São Paulo: Hucitec, 2011.

MANSIR, D. F. C. Voices from Jerusalem, recommendations for the Religious and Civil Governance of Jerusalem. The Union Institute Graduate School Cincinnati, Ohio, 1999.

MARAVAL, P. The Earliest Phase of Christian Pilgrimage in the Near East (before the 7th Century). In: Dumbarton Oaks Papers, n. 56. Ed. Alice-Mary Talbot. Published by Dumbarton Oaks Research Library and Collection Washington, D.C., Issue year 2002. www.doaks.org/etexts.html 
MERYON, R. General Gordon on Golgotha, Gordon's letters to Sir John Cowell 1883.

Jerusalem: The Garden Tomb Publish, 2012.

MINISTÉRIO do Turismo de Israel. E-mail trocado em 30 de janeiro de 2018 com Renata Vuono (Depto. Marketing), em que foram passadas estatísticas oficiais do turismo em 2017, além dos projetos turísticos em andamento e declarações oficiais.

MUKADDASI, Description of Syria, including Palestine Mukaddasi (Circ. 985 A.D.). Translated from the arabic and annotated by Guy Le Strange. London, 1896.

PARTIN, H. B. Pilgrimage to Jerusalem: Jewish, Christian, Muslim. Encounter, 46 n. 1, Winter, 1985, p. 15-35. Publication Type: Article.

PAULA, Letter of Paula and Eustochium to Marcella (386 A.D.), Charles W. Wilson (Org.), Aubrey Stewart (trad.). In: The Library of the Palestine Pilgrims' Text Society. London: Palestine Pilgrims’ Text Society, 1889.

POLONER, J. John Poloner's description of the Holy Land (Circa 1421 A.D.), Aubrey Stewart (trad.). London: Palestine Pilgrims Text Society, 1894.

SAEWULF (1102, 1103 A.D.). Trad. J. Canon Brownlow. In: The Library of the Palestine Pilgrims' Text Society. London: Palestine Pilgrims' Text Society, 1892.

SMITH, J. A. "My Lord's Native Land": Mapping the Christian Holy Land. In: Church History, v. 76, n. 1, mar. 2007, p. 1-31. Cambridge University Press. Disponível em: http://www. jstor.org/stable/27644922 e acessado em: 16.03.2016.

TAYLOR, J. E. Christians and the Holy Places, The Myth of Jewish-Christian Origins. Oxford: Clarendon Press, 1993.

TORRÃO FILHO, A. A arquitetura da alteridade, a cidade luso-brasileira na literatura de viagem (1783-1845). São Paulo: Hucitec, 2010.

WILLIBALD, The hodoeporicon of Saint Willibald (Circa 754 A.D.), trad. Rev. Canon Brownlow. In: The Library of the Palestine Pilgrims' Text Society. London: Palestine Pilgrims' Text Society, 1895.

WILSON, C. W. The Holy Places Visited by Antoninus Martyr (circ. 500-530), Aubrey Stewart (trad.). In: The Library of the Palestine Pilgrims' Text Society. London: Palestine Pilgrims' Text Society, 1887.

WILSON, C. W. The Letter of Paula and Eustochium to Marcella (386 A.D.), Aubrey Stewart (trad.). In: The Library of the Palestine Pilgrims' Text Society. London: Palestine Pilgrims' Text Society, 1889.

Submetido em: 15-2-2019

Aceito em: 20-8-2019 